\title{
Experimental cyclic behaviour of shear masonry walls reinforced with single and double layered Steel Reinforced Grout
}

\author{
Larisa Garcia-Ramonda ${ }^{\mathrm{a}, 1}$, Luca Pelà ${ }^{\mathrm{a}}$, Pere Roca ${ }^{\mathrm{a}}$, Guido Camata ${ }^{\mathrm{b}}$ \\ ${ }^{a}$ Department of Civil and Environmental Engineering, Universitat Politècnica de Catalunya \\ (UPC-BarcelonaTech), Jordi Girona 1-3, 08034 Barcelona, Spain. \\ ${ }^{b}$ Department of Engineering and Geology, University "G. D'Annunzio" of Chieti-Pescara, \\ viale Pindaro 42, I-65127 Pescara, Italy
}

\begin{abstract}
Recent research on the mechanical characterisation of Steel Reinforced Grout (SRG) has highlighted its excellent performance as strengthening solutions for masonry structures. Using SRG with limited fabric density ensures a good textile-matrix interlocking, preventing at the same time the failure due to slippage or debonding from the substrate. This paper presents an experimental investigation on the use of SRG as in-plane strengthening solution for shear masonry walls composed of handmade solid clay brick and hydraulic lime mortar. Cyclic shear compression tests were carried out on walls strengthened with SRG comprising low density steel sheets (LDS). The SRG was applied on both faces of the walls with a strip configuration, using one and two layers of LDS. The experimental programme aimed to study the influence of the number of textile layers on the in-plane response of strengthened masonry walls in terms of failure mechanism, load-bearing capacity, energy dissipation, and ductility.

Keywords: Seismic behaviour, Seismic retrofit, Shear wall, Masonry, SRG, FRCM, TRM, Damping, Energy dissipation, Ductility
\end{abstract}

\footnotetext{
Email addresses: larisa.garcia.ramonda@upc.edu (Larisa Garcia-Ramonda), luca.pela@upc.edu (Luca Pelà), pere.roca.fabregat@upc.edu (Pere Roca), g.camata@unich.it (Guido Camata)

${ }^{1}$ Correponding Author
} 


\section{Introduction}

2 Due to the availability of the component materials, masonry is one of the oldest construction techniques used worldwide. The assembly of units with dry

4 joints or with mortar makes it extremely complex to assess. Clay brick masonry is one of the most recurrent construction materials found in the Mediterranean

6 built heritage. Owing to the material's almost null tensile strength, among other mechanical features, masonry buildings show large vulnerability to earthquake

s action. Past seismic events have evidenced masonry's high vulnerability [1, showing the necessity to improve the seismic performance of the existing shear

10 walls. In the last decades, different strengthening techniques have received growing interest from the scientific community. Among these techniques, the

12 most profusely used are Fibre Reinforced Polymer (FRP) and Textile Reinforced Mortar (TRM).

A particular case of TRM, commonly known as Steel Reinforced Grout (SRG), has shown outstanding mechanical performance when applied on clay brick masonry walls [2, 3]. SRG consists typically of ultra high tensile strength steel cords embedded in mortar matrix and bonded to the surface of the reinforced structural element. Thanks to its high strength-to weight ratio, SRG provides a significant improvement of the structural response of existing masonry walls with minimum mass increase. Steel-based reinforcements also offer excellent mechanical performance, thanks to their effective cord-to-mortar interlocking, while having relatively low cost. So far, the research effort on SRGs has been mainly devoted to its mechanical characterization in terms of tensile behaviour and substrate-to-composite bond performance. Some experimental investigations involving masonry walls retrofitted with SRG solutions have been carried out on different masonry typologies by means of Diagonal Compression Test [2, 3, 4, while few cyclic shear compression tests have been performed on clay brick masonry walls $[5$.

De Santis et al. [6] characterised SRG systems by carrying out shear bond test on unidirectional steel grids of different densities embedded in lime-based mortar 
matrix. The retrofitting solutions were applied on weak modern clay brick and historical clay brick substrates. The authors observed that the good cord-mortar interlocking impedes the sliding of the textile within the matrix, and the high tensile strength of the steel cord avoids the tensile rupture. Most of the failures were due to detachment at the textile-matrix interface. However, reinforcement solutions involving higher density textiles showed lower bond strength due to the fact that the smaller cord spacing affected the load transferring capacity. The

38 authors concluded that the bond performance of SRG relies on the continuity of the mortar matrix in the cross section of the reinforcement, which in turn depends on the penetration of the mortar into the voids of the textile. Therefore, less dense textiles yielded higher exploitation ratios of their tensile strength.

42 Such conclusion was also validated by Wang et al. [7], who investigated the bond behaviour of SRG involving two textile densities. The authors observed

44 that the two densities led to different failure modes and exploitation ratios. De Santis et al. 6] observed through a Round Robin Test (RRT) [8] that the most

46 recurrent failure occurs at the textile-matrix interface and is associated to good exploitation ratios of the textile's tensile strength.

48

Most of the research developed on the bond behaviour of SRG, has been performed using a single brick as substrate and therefore neglecting the influence 50 of the masonry mortar joints in the bond behaviour. Santandrea et al. [9, 10] designed and performed an extensive experimental campaign to study the bond

${ }_{52}$ behaviour between SRG and masonry joints. The presence of the mortar joints provided a more realistic evaluation of the effective bonded length required

54 for full load transfer. A total of seventy-eight samples of unidirectional high strength steel fibre strips, with different bonded length, embedded in a limebased hydraulic mortar were applied on masonry substrate and tested. The results evidenced that for bonded length up to $100 \mathrm{~mm}$ the failure mode was always due to debonding from the substrate. Conversely, specimens with bonded length greater than $200 \mathrm{~mm}$ were mainly characterised by failure at the textile${ }_{60}$ matrix interface. This outcome confirmed previous findings [1], in which the effective bonded length resulted equal or greater than $200 \mathrm{~mm}$. 

to evaluate the effectiveness of SRG to improve the in-plane behaviour of different masonry typologies. Wang et al. 22 investigated two different steel cord densities, low and high density, applied on six grey clay brick masonry walls in three configurations corresponding to strips in a single direction, vertical or horizontal, and strips applied in both vertical and horizontal directions. In all the cases the failure modes were mainly characterised by debonding and delamination and no rupture of the steel cord was observed. The specimens retrofitted with a single direction of SRG underwent large stress concentration at the edges of the strips, leading to the detachment of the SRG layers from the substrate.

72 These results indicate that the efficiency of the reinforcement to enhance the in-plane response is influenced by the orientation of the SRG strips. Similar results were observed by Garcia-Ramonda et al. 3] through an experimental programme involving double-leaf clay brick masonry walls retrofitted with SRG

76 of low and medium density steel textiles. The experimental results also confirmed the better performance of the low density steel textile over the medium density one, due to the better interlocking between the textile and the matrix. As a result, it was concluded that the increase of the yarn density does not necessarily lead to an improvement of the structural performance.

The experimental results previously mentioned highlight the benefits of using 82 SRG with less dense steel textile embedded in a low strength lime-based mortar. The compatibility between the moderately weak mortar matrix and the masonry substrate allows a good bond at their interface, moving the failure towards the textile-matrix interface. The sparser is the textile, the better is the interlocking

86 at textile-matrix level, which avoids slippage of the textile and induces the debonding within the matrix rather than the debonding from the substrate.

${ }_{88}$ The debonding within the matrix allows an optimal exploitation of the tensile strength of the steel textile [12].

90 The previous researches achieved different reinforcement ratios 13 by modifying the spacing between the steel yarns. However, the procedure affects the 92 mortar protrusion and, for high reinforcement ratios, it may compromise the 
textile-mortar interlocking.

Another possibility to increase the reinforcement ratio, without affecting the yarn spacing of the textile, consists in applying multiple layers of a sparser

96 textile. Only limited research [14, 15] has been done on the influence of the number of textile layers on the in-plane response.

Within this context, an experimental programme was designed to better understand the in-plane behaviour of clay brick masonry walls laterally loaded under three different configurations: unreinforced, retrofitted with one layer of low density steel textile (LDS), and retrofitted with two layers of LDS. The experimental programme involved the execution of cyclic Shear Compression Test (SCT), on six specimens with the double purpose of assessing the efficiency of the SRG solutions as seismic retrofitting technique and investigating the influence of the number of LDS layers on the in-plane response of retrofitted masonry. Given the lack of experimental data regarding the bond behaviour between the different layers of LDS, and knowing the critical importance of the bond behaviour on the overall performance of the composite system, this study is expected to provide relevant experimental information for the design of SRG-based retrofitting of masonry structures.

\section{Specimens features}

\subsection{Materials and Construction}

In order to represent a common type of historical masonry, the wall specimens investigated in the present research were built with fired clay bricks and low-strength lime masonry. Handmade solid clay bricks fired with traditional procedures were used for the assemblage of six double leaf masonry walls with nominal dimensions $1270 \times 1270 \times 310 \mathrm{~mm}^{3}$. The specimens were built in Flemish bond with 21 courses and $15 \mathrm{~mm}$ thick mortar joints, see Figure 1 .

The brick's mechanical properties were determined based on compression and flexural tests following the EN 772-1:2011 [16] and the EN 772-6:2001 [17]. Twenty prismatic brick samples with dimension $100 \times 100 \times 40 \mathrm{~mm} 3$ were cut 


\subsection{Strengthening}

146

two layers of unidirectional ultra-high tensile strength steel cords of low density

from the units to evaluate the compressive strength. The resulting normalized compressive strength $f_{b, c}$ was equal to $17.99 \mathrm{MPa}$ (C.o.V 8.30\%). The flexural strength $f_{b, f}$ was determined by three-point-bending tests on full bricks with a resulting value of $2.44 \mathrm{MPa}$ (C.o.V 20.0\%). To replicate a low strength historical lime mortar, the compressive strength of the commercial hydraulic lime-based premix was reduced with limestone filler addition using the approach provided in [18. Following the EN 1015-11:1999 [19] the mortar flexural strength $f_{m, f}$ was evaluated on nine prismatic specimens for each wall built, while the compressive strength $f_{m, c}$ was assessed on the eighteen halves produced by the splitting of the samples under flexure. The flexural and compressive strength yielded values equal to $0.57 \mathrm{MPa}$ (C.o.V 25.4\%) and 2.54 MPa (23.60\%), respectively.

The compressive behaviour of the masonry under study was investigated by Segura et al. 20]. The obtained average strength was $6.50 \mathrm{MPa}$ (C.O.V 9\%) and the average Young's modulus was $2318 \mathrm{MPa}$.

Finally, a concrete beam was cast on top of the specimens to allocate the set-up device in charge of applying the cyclic horizontal displacements. The constructed walls were stored under laboratory conditions during the 28 days required for the curing of the mortar. After this time, the specimens were strengthened by professional workers from the manufacturer company. Among the six specimens built, two were unreinforced. The remaining four specimens were retrofitted with SRG strengthening systems with single and double layers. The specimens were strengthened using a strip configuration for SRG, following the procedure show in Figure 2 . (LDS), 1.57 yarn/cm, embedded in a lime-based mortar matrix. Table 1 reports the relevant properties of the textile as provided by the manufacturer and some specific studies [6, 11, [7].

The mortar matrix was a premixed NHL 3.5 natural hydraulic lime of M15 


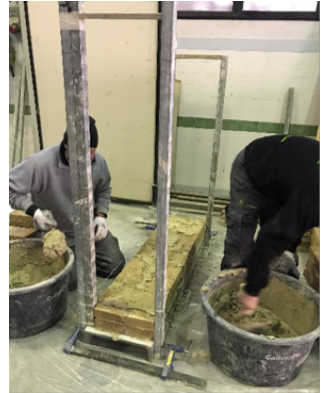

a)

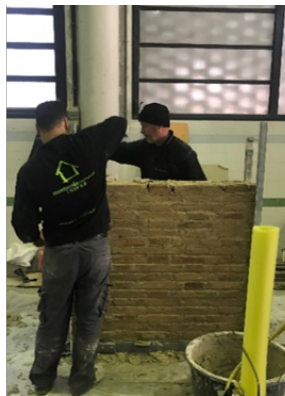

b)

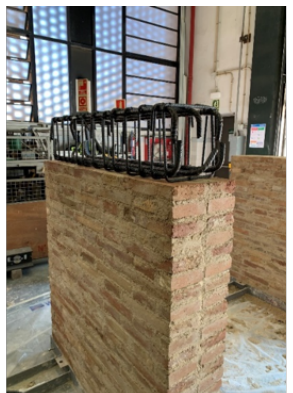

c)

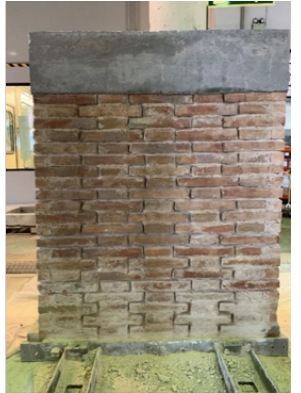

d)

Figure 1: Procedure for construction: a) placing of the rulers for the construction, b) construction of the wall in Flemish bond, c) rebars placing for the concrete beam located on top of the specimen, d) specimen finished and stored under laboratory conditions

Table 1: Mechanical properties of the textile used for the reinforcement of the walls as provided by the manufacturer and some specific studies [6, 11, 7

\begin{tabular}{cccccc}
\hline Poung's & $\begin{array}{c}\text { Ultimate Tensile } \\
\text { Strength }\end{array}$ & Strain at failure & Thickness & $\begin{array}{c}\text { Tensile capacity } \\
\text { from shear bond test } \\
\sigma_{s l, t}^{\dagger}[\mathrm{MPa}]\end{array}$ \\
\hline LDB & 190 & 2800 & 0.015 & 0.084 & 2096 \\
\hline
\end{tabular}

$\dagger$ for further information [6, 11, 17

class according to EN 998-2:2010 [21]. Following the EN 1015-11:1999 [19], prismatic samples were cast into metallic moulds with dimensions $160 \times 40 \times$ $40 \mathrm{~mm}^{3}$ after the preparation of every batches of mortar. The flexural strength $f_{r m, f}$ was evaluated on six prismatic specimens for each wall built, while the compressive strength $f_{r m, c}$ was assessed on the twelve halves produced by the splitting of the samples under flexure. The flexural and compressive strength yielded the values equal to $3.59 \mathrm{MPa}$ (C.o.V 6.70\%) and $12.90 \mathrm{MPa}(7.20 \%)$, respectively. The Young's modulus of the mortar matrix, $E_{r m, s t}$ is equal to 9 GPa as provided by the manufacturer.

To implement the strengthening, the surfaces of the walls were prepared by removing the dust and creating grooves along the mortar joints in order to generate the necessary grip between the wall's surface and the mortar matrix 


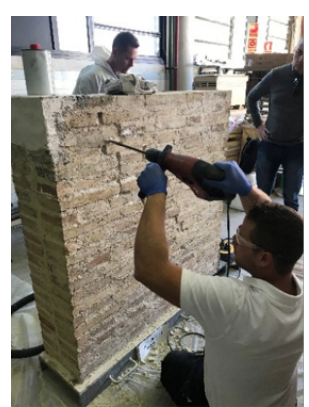

a)

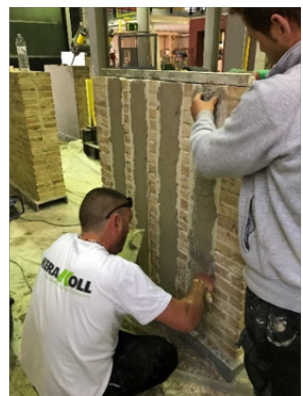

b)

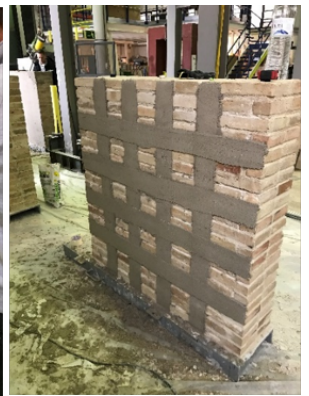

c)

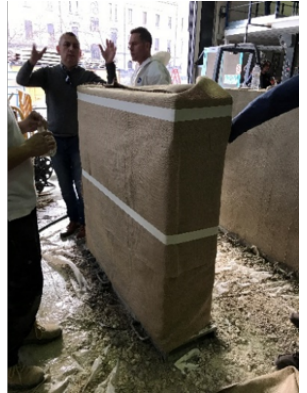

d)

Figure 2: Procedure for the application of the SRG strengthening system: a) creation of grooves along the mortar joints, b) application of the first layer of mortar, c) finished look of the wall retrofitted with $\mathrm{SRG}, \mathrm{d}$ ) wrapping of the specimens with wet burlap for curing

of the SRG. The specimens were wet with abundant water to prevent masonry from absorbing the water during the application of the composite. The first layer of mortar matrix was applied on the surface of the specimen. Then the textile was embedded in the matrix by applying a light pressure on the textile to guarantee the right adherence to the support and the mortar penetration into the voids between the yarns. A second layer of mortar matrix was applied to cover completely the strips. The final thickness of the SRG reinforcement varied between 8 to $10 \mathrm{~mm}$. The reinforcement was applied symmetrically on each specimen. Once the hardening of the mortar had begun, the faces were wet to favour the curing and were then wrapped with burlap fabric, which was kept wet for the following 7 days. Once the fabric was wet, it was wrapped with plastic sheets to preserve the humidity of the specimens.

This experimental campaign is the second part of a larger experimental programme involving two different in-plane testing methods, Diagonal Compression

Test (DCT) and Shear Compression Test (SCT), as well as different reinforcement configurations. Previous DCT experiments carried out on the specimens retrofitted with medium density steel (MDS) SRG showed unsatisfactory results due to the excessive steel density [3. The reduction of the grid spacing of the textile provided lower interlocking to the mortar matrix which led to 
the lower performance of the reinforcement. Consequently, this research invest-

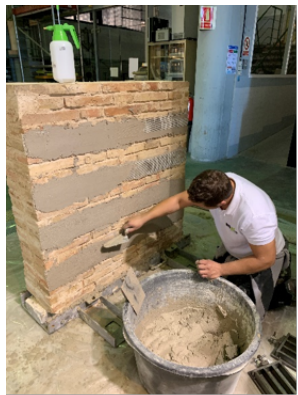

a)

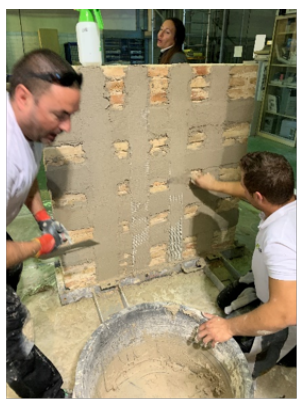

b)

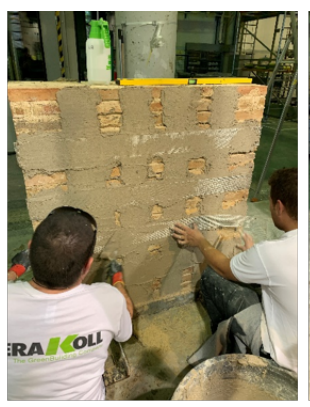

c)

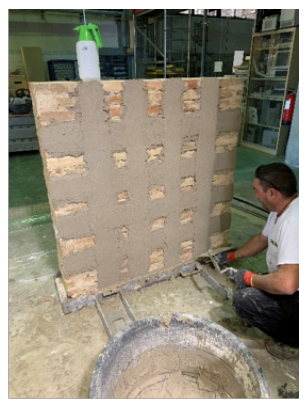

d)

Figure 3: Procedure of application of double-layer strip configuration of LDS: a) application of the first horizontal layer of SRG, b) application of mortar in the areas with no intersection, c) application of the second horizontal layer of SRG, d) application of mortar to obtain an even finished surface

\section{Experimental programme}

To investigate the performance and the efficiency of SRG as a seismic retrofitting technique, a cyclic shear compression test was designed following the standard FEMA 461 222. From the response of the specimens it was possible to evaluate key parameters for understanding the in-plane response. 


\subsection{Set-up}

Figure $4 a$ and Figure 5 show the general view of the experimental set-up utilized to perform the cyclic shear compression test. During construction, the samples were laid on a metallic C-profile filled with concrete, which allowed the sliding shear failure to occur potentially during the test. In addition, the base was constrained at both ends by two T-shape devices. Both the base and the end-devices were fixed to the strong floor of the laboratory by means of posttensioned steel bars. On top of the wall a reinforced concrete beam was placed. This element had the double function of ascertaining a smooth distribution of the vertical load, as well as hosting the plates receiving the horizontal cyclic loading induced by the actuator. The vertical load was applied with two jacks of $1000 \mathrm{kN}$ capacity each over a stiff metallic $\mathrm{H}$ profile stiffened with ribs laid on top of the RC beam. The jacks reacted against a stiff frame anchored to the strong floor. Between the RC beam and the metallic profile, a $3 \mathrm{~mm}$ thick Teflon sheet and a $3 \mathrm{~mm}$ thick PVC sheet were inserted to provide a smooth horizontal surface and reduce the friction between both. Between the RC beam and the PVC sheet a layer of cement-based mortar, with thickness of 5 to $10 \mathrm{~mm}$, was inserted in order to level the end surface and avoid stress concentrations due to irregularities.

The shear compression tests comprised two steps. Firstly, the vertical force $V$ was gradually applied under force control. The valves of the jacks were closed once the designed compression stress was reached. Such compression stress was taken equal to $\sigma_{v}=0.3 \mathrm{MPa}$, which corresponds to the typical vertical load at the base of a two-storey masonry building. Secondly, the horizontal shear force $H$ was applied with a hydraulic actuator anchored to a reaction wall. The actuator had a pushing and pulling capacity of $350 \mathrm{kN}$ and $250 \mathrm{kN}$, respectively. Two steel plates (of $530 \times 300 \times 30 \mathrm{~mm}^{3}$ ) connected by 4 steel rods of $40 \mathrm{~mm}$ diameter were mounted aligned with the horizontal actuator. One of the plates was connected

226 to the horizontal actuator by means of a hinge, enabling the application of cyclic loading in the horizontal direction, as shown in Figure 4 - $b$ - $c$. With the valves of the actuators closed, no displacement or rotation of the top of the 
wall was possible at this stage, and applying horizontal load induced a double

\subsection{Crack pattern and hysteretic response}

248 tested specimens. Figure 7 shows the experimental force-displacement curves

250 horizontal load also produced an increase of the vertical one due to the wall vertical confinement.

A combination of instruments was placed on both specimens' faces in order to capture their in-plane response. Ten linear variable displacement transducers (LVDT), with a displacement range of $+/-5 \mathrm{~mm}$ and a precision of $5 \mu \mathrm{m}$, were lift and relative sliding between the wall and its base. They allowed controlling the cracking of masonry, as well as the potential rocking of the specimens. In addition, eight potentiometer displacement transducers were utilized, as redundant instrumentation, to obtain measurements of the diagonal and vertical displacement. Finally, two laser sensors measured the imposed horizontal displacement. The vertical load was measured by means of four pressure transducers and the horizontal load by the actuator's inner load cell. The crack pattern and damage evolution were also monitored through Digital Image Correlation (DIC) and video recording.

\section{Experimental Results}

\section{Fichereshows the crattern and hysteretic response}

Figure 6 shows the crack patterns developed at the end of the test for all the obtained under the applied cyclic in-plane loading. Figure 7 also shows the resulting envelope curves of the cyclic responses. These curves were derived

252 from the experimental hysteretic curves and were constructed by connecting the peak force at the first cycle of each displacement amplitude. The positive 254 direction is the direction in which the horizontal hydraulic actuator pulls the specimen whereas the negative one is the direction in which the actuator pushes bending condition [23]. As a consequence of the testing method, increasing the 256 the specimen. The displacement was measured at the top of the wall. The corresponding drift represents the lateral displacement over the total height of 


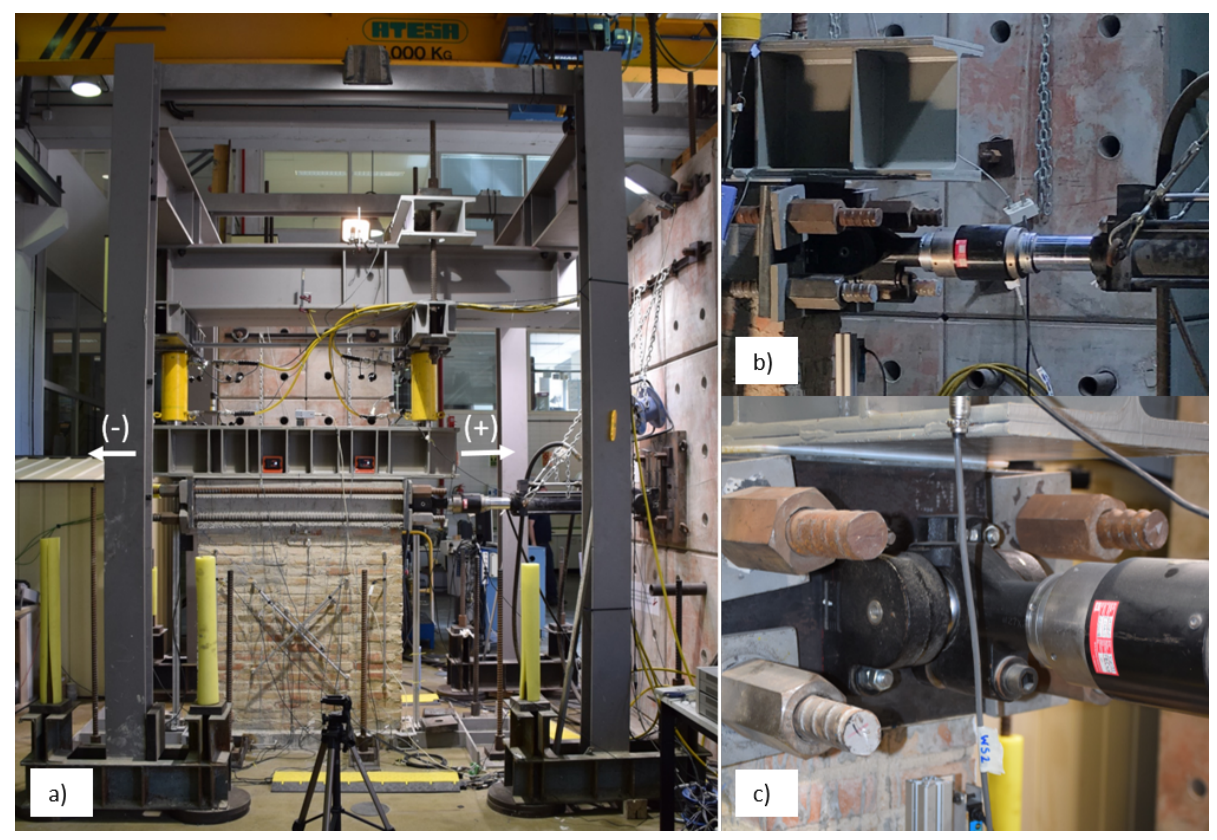

Figure 4: a) General view of the Shear Compression Test set-up, b) detail of the plate and rods connected to the horizontal actuator, c) hinged connection allowing the cyclic loading.

the specimen, expressed as a percentage. Table 2 summarizes the main results of the SCT for each specimen tested.

\subsubsection{URM walls}

The final damage of the URM walls (Figure 6 $a$ ) was characterised by a diagonal stair-stepped cracking through the mortar joints and by tensile splitting of some units. With increasing displacement amplitudes, the cracks developed until a wide crack was formed along each diagonal, leading to global failure. Both URM specimens presented a relatively brittle behaviour. The load increased linearly with the imposed displacement until the onset cracking, which was observed as a change of the slope of the load-displacement curves. These first cracks were visible, in the pushing direction, at the centre of the panel at an average displacement equal to $\delta_{c r}=5.5 \mathrm{~mm}$ (drift $\theta_{c r}=0.4 \%$ ). The maximum load was attained at an average displacement $\delta_{H_{\max }}=10.9 \mathrm{~mm}\left(\operatorname{drift} \theta_{H_{\max }}=0.9 \%\right)$ shortly after the concentration of cracks on each diagonal. The attainment of 


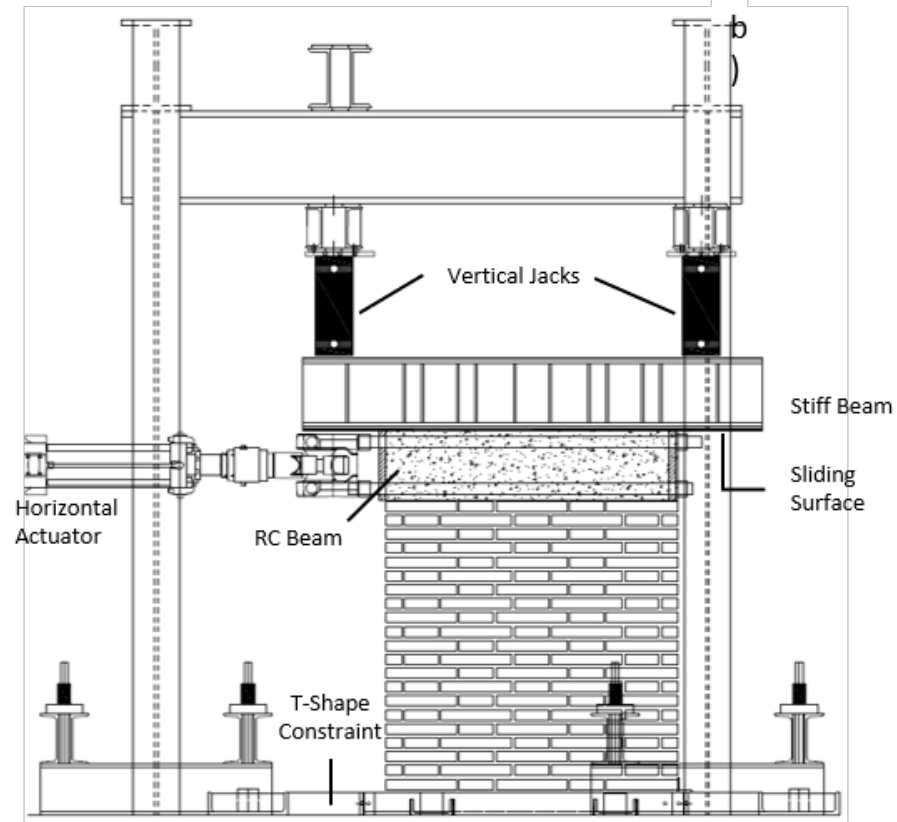

Figure 5: Set-up of the Shear Compression Test set-up

the peak load was followed by a sudden brittle failure. Due to the brittleness of the response, the walls were unable to withstand larger deformation once the maximum lateral force was attained.

\subsubsection{Walls retrofitted with one layer of $L D S$}

Figure 6 b $b$ shows the different failure mechanisms that led to the failure of the specimens with single-layer LDS. During the initial stages of loading, flexural cracks at the brick-bed joint interface were detected on the corners of both specimens. In the following cycles, the damage evolved differently for each specimen. Specimen LDS_1 showed a mixed mechanism combining diagonal tensile cracking on the pushing direction and frictional sliding on the pulling direction. As a result of the formation of several sliding interfaces in some bed joints, the crack pattern shows only one diagonal crack. Specimen LDS_2 showed tensile diagonal cracking evolving from the centre of the panel towards the corners, on both directions. 

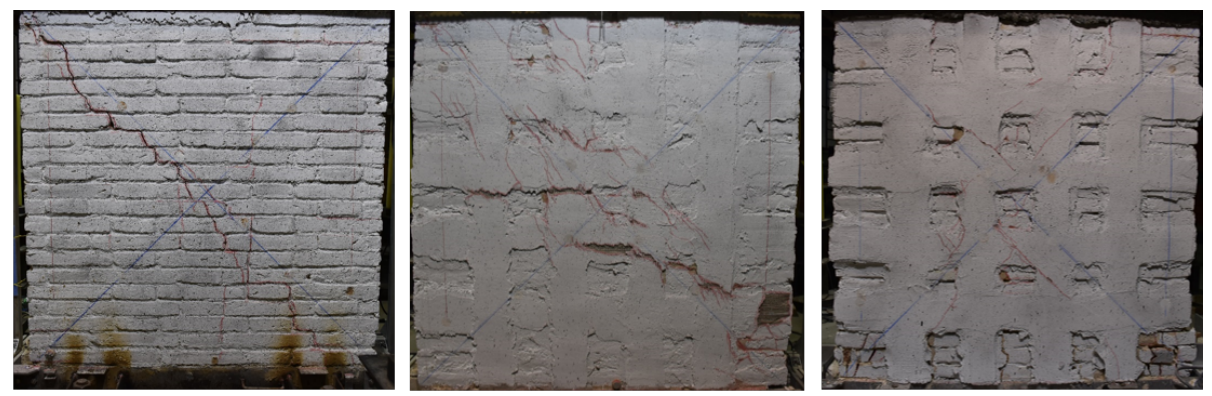

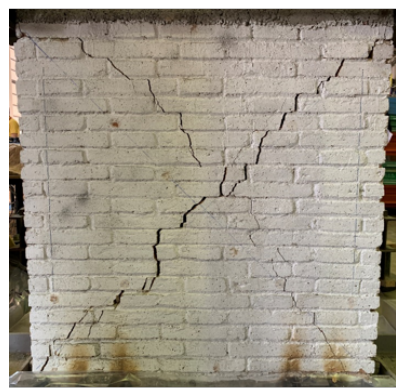

a)

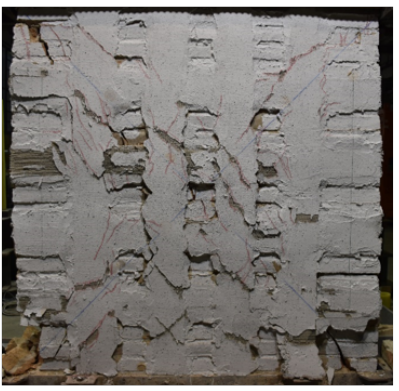

b)

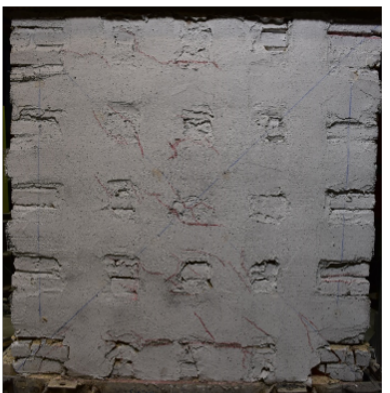

c)

Figure 6: Crack patterns at the end of the tests: a) URM_1 (up) and URM_2 (down), b) LDS_1 (up) and LDS_2 (down), c) LDS-DL_1 (up) and LDS-DL_1(down)

298

This difference on the failure mechanisms is also evidenced in the forcedisplacement curves of Figure $7 c-d$. The initial behaviour of both specimens was similar. On average, LDS specimens evidenced the first cracks at a displacement equal to $\delta_{c r}=7.83 \mathrm{~mm}\left(\theta_{c r}=0.6 \%\right)$. Compared with the URM specimens, the application of SRG provided larger capacity to sustain imposed displacements before cracking. This result evidences the effective role of the horizontal strips as crack arrestors. However, the different failure mechanisms experienced by the walls influenced significantly the behaviour after cracking and the displacement at which the peak load was attained. Specimen LDS_2 attained the maximum load at a displacement equal to $\delta_{H_{\max }}=14.3 \mathrm{~mm}\left(\theta_{H_{\max }}=1.1 \%\right)$ in both directions, while specimen LDS_1 attained its peak load at a larger displacement amplitude equal to $\delta_{H_{\max }}=24.1 \mathrm{~mm}\left(\theta_{H_{\max }}=1.9 \%\right)$. It is interesting to highlight that, in spite of this difference, the post peak response presented a similar feature in both specimens. After the attainment of the peak load, the 

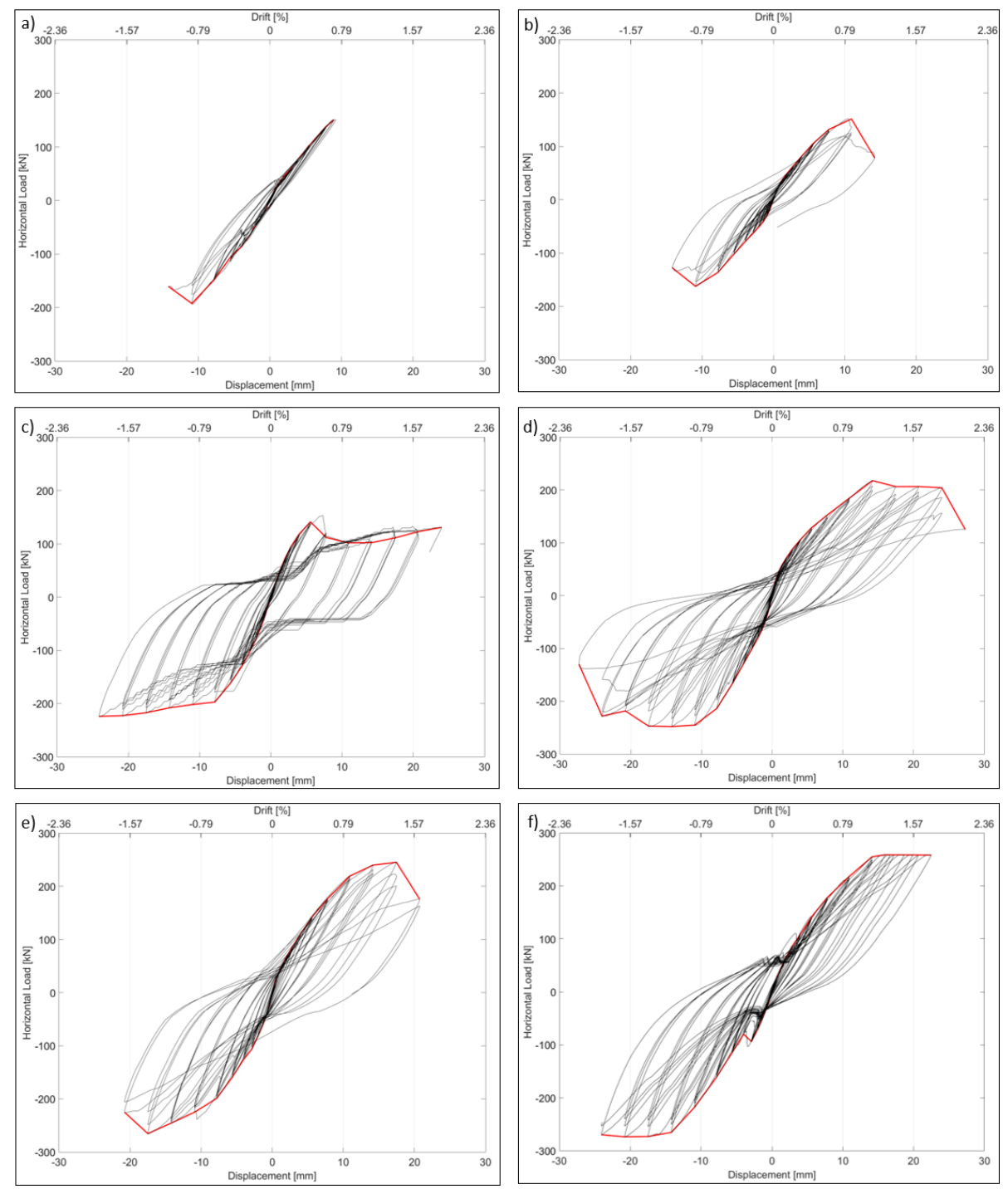

Figure 7: Experimental force-displacement curves at the end of the tests: a) URM_1, b) URM_2, c) specimen retrofitted with LDS strips LDS_1, d) specimen retrofitted with LDS strips LDS_2, e) specimen retrofitted with two layers of LDS strips LDS-DL_1, f) specimen retrofitted with two layers of LDS strips LDS-DL_2 
load was kept almost constant for several displacement amplitudes before the degradation of the lateral strength. This phenomenon may be due to a redistribution of the stresses throughout the strips of textile until they delaminate from the mortar matrix, which in turn experienced debonding from the masonry substrate. Figure 8 shows the crack pattern evolution on specimen LDS_2 along the diagonal corresponding to the pushing direction. The first three images correspond to the consecutive displacement amplitudes in which the load was almost invariable. The cracks evolved gradually until reaching the displacement amplitude equal to $\delta=20.7 \mathrm{~mm}$, at which delamination within the matrix and debonding took place, causing sudden strength loss. In the following displacement steps, the damage caused by debonding increased until reaching the final crack pattern (see Figure 6 b $b$ ). Similarly, LDS_1 experienced a gradual evolution of its diagonal cracking. However, and due to the sliding surface generated, this specimen did not develop a post-peak response.

After reaching the peak load both LDS specimens experienced delamination within the matrix followed by spalling of the mortar in the areas heavily cracked. This outcome is in agreement with the response revealed by previous studies on SRG systems subjected to single lap bond tests [6, 8, 10, 7]. In the following levels of displacement the crack patterns were characterised by a progressive debonding from the substrate of the horizontal and vertical strips. Finally, at the largest displacement amplitude specimen LDS_2 experienced toe-crushing on both directions. No rupturing of the steel cords was observed in either of the specimens. Therefore, the total tensile strength of the SRG strips was not fully attained.

Regarding the overall performance, in specimen LDS_2, the SRG with one layer of LDS provided a substantial improvement in lateral load-bearing capacity, with a peak load $42 \%$ larger than the corresponding value of the URM walls. This percentage has been obtained as average of the peak load obtained 22 for both directions. This specimen also showed a remarkable improvement, of about $90 \%$, in displacement capacity compared with the URM walls. The results of specimen LDS_1 are considered less meaningful due to its failure mode 

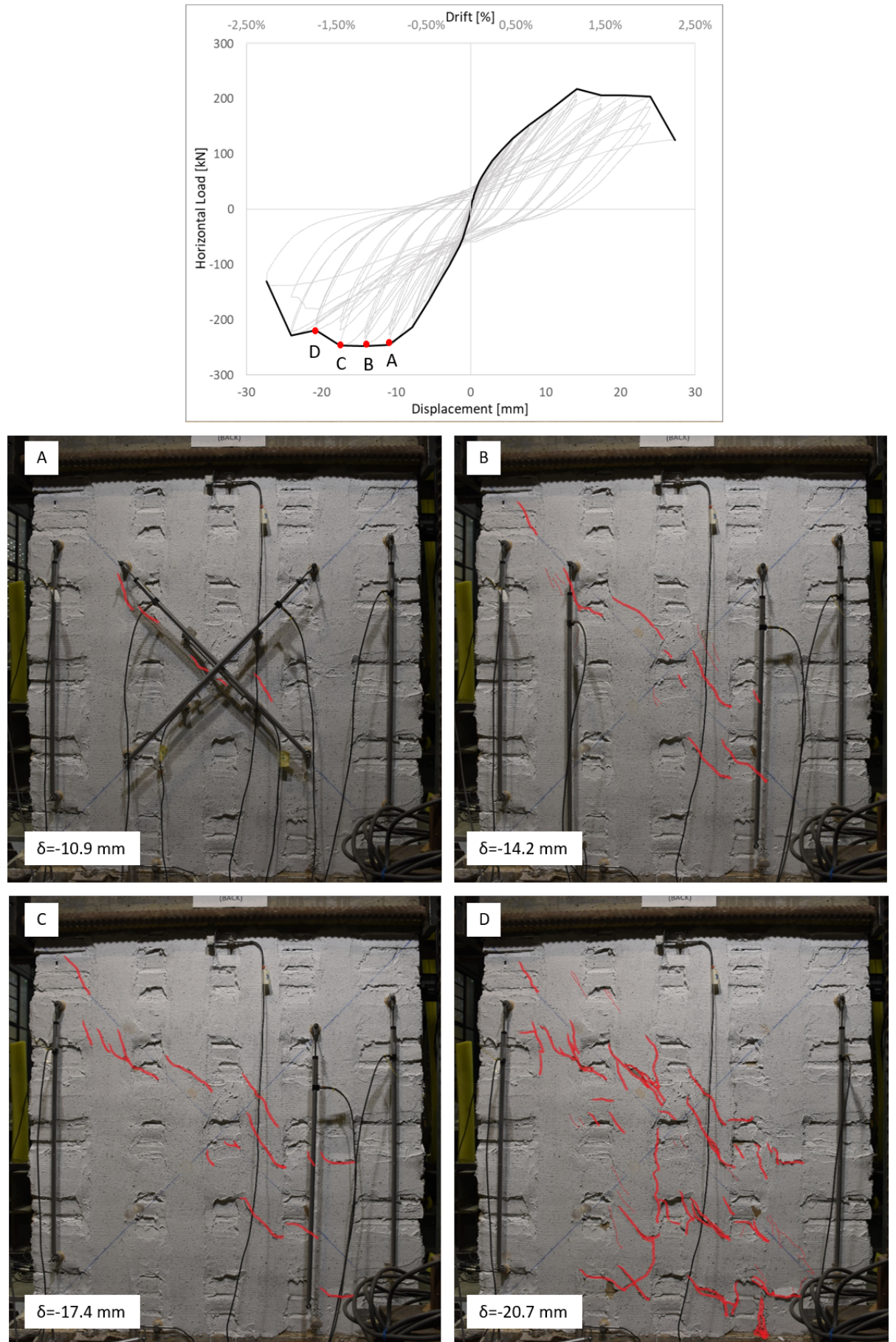

Figure 8: Crack pattern evolution in the pushing direction of specimen LDS_2 
and asymmetric response. Specimen LDS_1 attained, in the negative direction,

a peak load $46 \%$ larger than the one in the positive direction.

\subsubsection{Walls retrofitted with two layers of $L D S$ ( $L D S-D L)$}

Specimens retrofitted with two layers of LDS strips failed due to toe-crushing on both directions. Figure 6 c shows the diagonal loading path followed from

the top corner of the specimen up to the bottom opposite corner, especially in the pushing direction.

The first cracks were visible at an average displacement equal to $\delta_{c r}=7.84$ $\mathrm{mm}\left(\theta_{c r}=0.6 \%\right)$. As expected, the second layer of LDS had almost null influence on the initial linear elastic response of the retrofitted masonry. In fact, Table 2 and Figure 9 shows similar values of effective stiffness $K_{e}$. Such stiffness is defined as the secant stiffness to the experimental envelope curve at the onset of cracking [24]. However, the second layer of LDS influenced significantly on

344 the response after cracking. The peak load was attained at a slightly larger displacement equal to $\delta_{H_{\max }}=17.5 \mathrm{~mm}\left(\theta_{H_{\max }}=1.4 \%\right)$ with a concentration of wide cracks on the bottom corners. Figure $7 \mathrm{f} e$ shows that shortly after the attainment of the peak load specimen LDS-DL_1 experienced a rapid degradation of the lateral load-bearing capacity. This failure was the consequence of the material loss on the compressed zone, which led to the ending of the test. In the case of specimen LDS-DL_2 the abrupt degradation of the lateral load-bearing capacity was not observed. The damage on the corners led to the appearance of horizontal flexural cracks in the mortar bed joints located on top of the them. These cracks allowed the uplift of the side of the walls that was in tension, with a consequent increase of the compressive stress on the opposite corner. In spite of the masonry crushing, these cracks allowed the specimen to continue withstanding larger imposed displacements without losing its lateral capacity. Shortly after, the specimens experienced a complete crushing of the brickwork under compression, followed by a localised debonding of the vertical strips' end at the corners. Unlike specimens retrofitted with one layer of reinforcement, and as the consequence of the masonry crushing, specimens LDS-DL did not 
show large damage due to debonding or delamination.

Regarding the overall performance, the SRG with two layers of LDS showed, on average, a remarkable increment in both lateral-load bearing and displacement capacity, of $59 \%$ and $89 \%$ respectively, when compared to URM specimens. The addition of the extra layer of reinforcement only represents a moderate enhancement in lateral load-bearing capacity of about $13 \%$ when compared to the one-layer LDS configuration, while almost no additional enhancement was observed on the displacement capacity.

In summary, by increasing the number of layers of the textile, the failure mode shifted from shear failure to toe-crushing of masonry. Such change indicates that the level of strengthening was excessive. According to the Italian guideline [25], the contribution of the retrofitting solutions must not lead to the failure of the compressed strut. Therefore, it must be verified that the shear capacity does not exceed the compressive capacity following Eq. (1), where $t$ is the thickness of the wall, $f_{c}$ is the compressive capacity of masonry and $d_{f}$ 376 is the distance between the compressed area and the area in tension. In the present research the compressive capacity of the wall $V_{t, c}$ was computed equal to $245 \mathrm{kN}$. Figure 9 shows this limit value of the compressed strut and the experimental curves of all tested specimen. It can be clearly seen that for both LDS-DL specimens the peak load exceeded such limit and therefore failed due to masonry crushing.

$$
V_{t, c}=0.25 \cdot f_{c} \cdot t \cdot d_{f}
$$

\section{Comparison of solutions}

As expected, the two reinforcement configurations evidenced the excellent in-plane performance of SRG strengthened walls. The adequacy of this type of reinforcement has to be analysed, however, through the improvement of relevant parameters characterizing the in-plane seismic response of masonry walls. These 


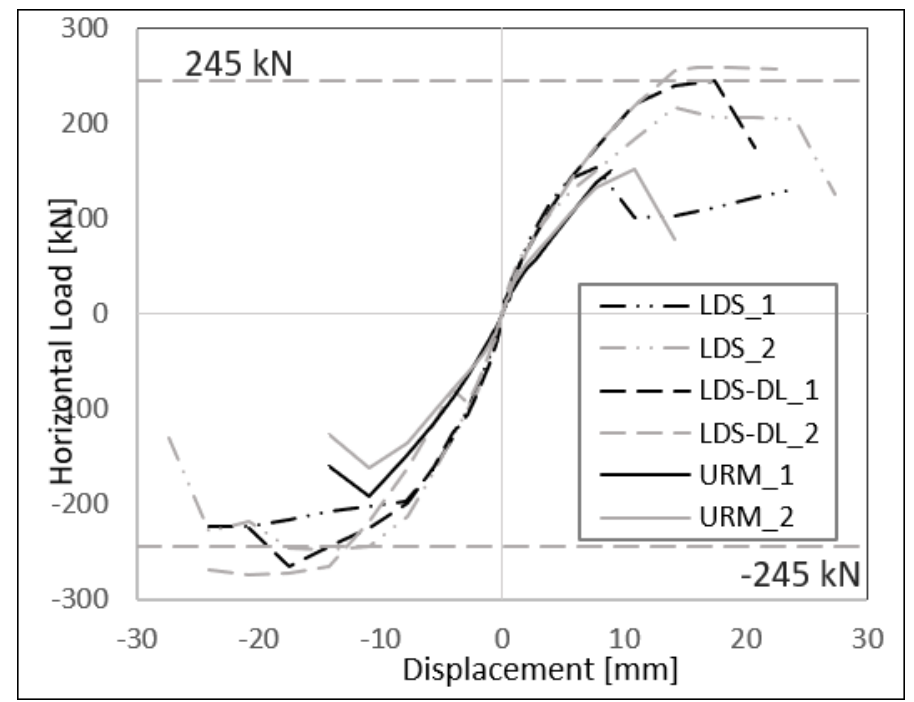

Figure 9: Experimental envelope curves of all specimens compared with the limit value of the compressive strength of masonry according to [25] 26]

parameters include the ductility $\mu$, the cumulative energy dissipation $E_{D}$, and the damping coefficient $\xi_{\text {eq }}$.

Table 2: Summary of the main results. Brackets show the values in [push, pull] directions

\begin{tabular}{|c|c|c|c|c|c|c|}
\hline & URM_1 & URM_2 & LDS_1 & LDS_2 & LDS-DL_1 & LDS-DL_2 \\
\hline$H_{\max } \quad[k N]$ & {$[-192.4,150.7]$} & {$[-162.9,151.6]$} & {$[-222.0,147.7]$} & {$[-242.5,213.3]$} & {$[-253.6,240.8]$} & {$[-273.2,257.4$} \\
\hline$\delta_{y} \quad[m m]$ & {$[-8.53,8.53]$} & {$[-8.38,7.68]$} & {$[-8.85,5.26]$} & {$[-8.90,10.91]$} & {$[-9.98,10.61]$} & {$[-13.27,11.31$} \\
\hline $\begin{array}{ll}\delta_{u} & {[m m]}\end{array}$ & {$[-14.16,14.16]$} & {$[-13.95,12.26]$} & {$[-24.1,9.38]$} & {$[-25.05,25.26]$} & {$[-20.76,19.77]$} & {$[-24.06,22.48$} \\
\hline$\mu$ & 1.66 & 1.63 & 2.33 & 2.56 & 1.97 & 1.90 \\
\hline$\Delta \mu \quad[\%]$ & - & - & $42 \%$ & $56 \%$ & $20 \%$ & $16 \%$ \\
\hline$E_{D}[k N-m m]$ & 1337 & 2700 & 15611 & 13982 & 12747 & 13780 \\
\hline$\Delta E_{D} \quad[\%]$ & - & - & $673 \%$ & $596 \%$ & $532 \%$ & $583 \%$ \\
\hline$\xi_{e q}$ & 3.39 & 3.24 & 3.96 & 3.80 & 4.44 & 4.54 \\
\hline$\Delta \xi_{e q} \quad[\%]$ & - & - & $20 \%$ & $15 \%$ & $34 \%$ & $37 \%$ \\
\hline$K_{e}[k N / m m]$ & 21 & 19 & 28 & 24 & 24 & 20 \\
\hline
\end{tabular}




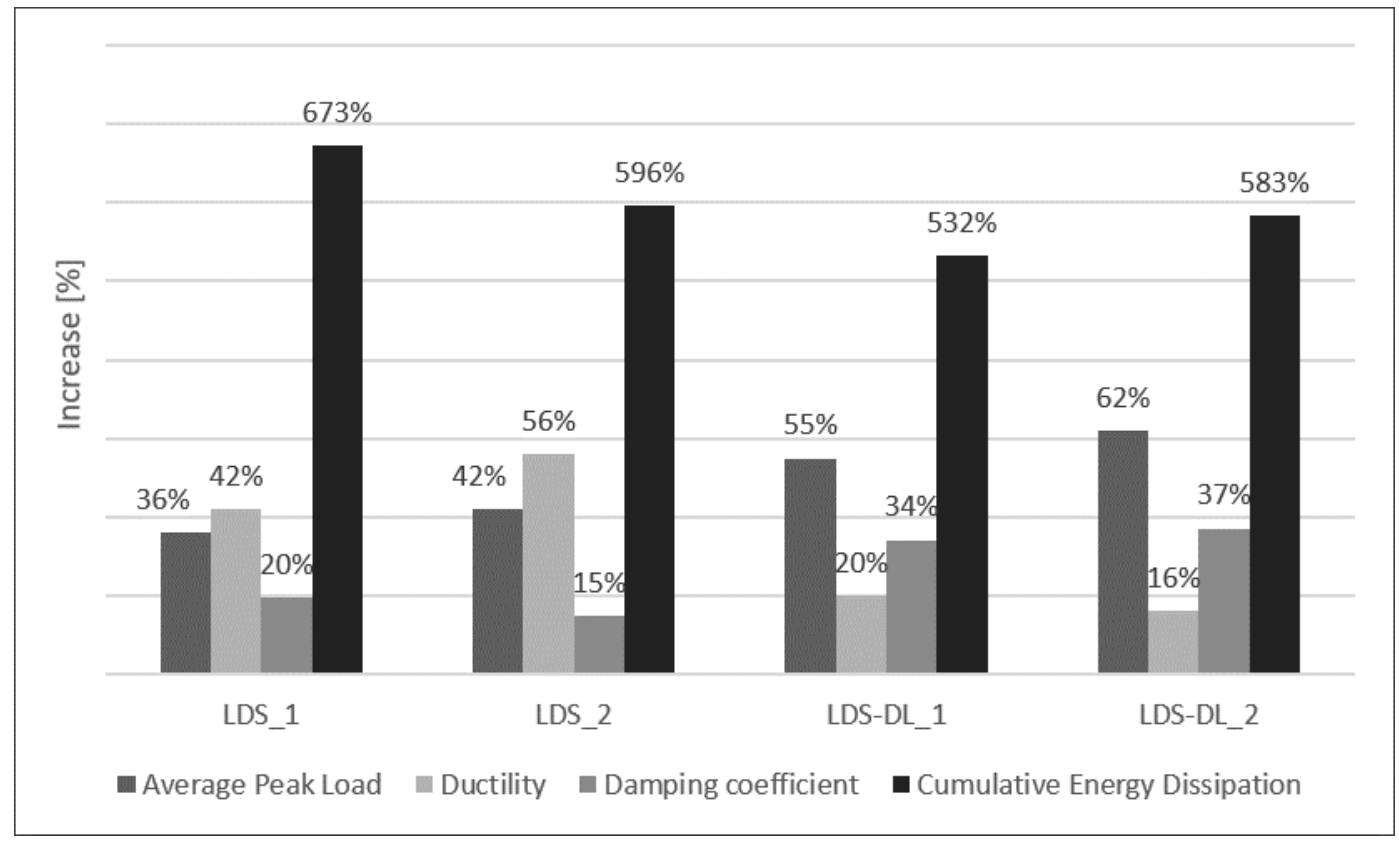

Figure 10: Rate of enhancement of the main in-plane parameters of all the retrofitted specimens

Table 2 summarizes the experimental value of each parameter for all specimens tested. Figure 10 shows the increment of the main parameters for each specimen tested, i.e. in terms of peak load, ductility, damping coefficient, and cumulative energy dissipation. The histograms display the average values of the parameters for each specimen considering the positive and negative directions. The figure shows the meaningful enhancement provided by the SRG in comparison with the reference URM walls. A more detailed analysis of the variation of these parameters is presented below.

\subsection{Lateral load capacity and ductility}

In order to quantify the ductility, the experimental curves were idealised as bilinear diagrams. This procedure allows an unbiased comparison of the ductility of the tested specimens [24. The bilinear idealization is characterised by three points. The cracking drift $\delta_{c r}$ corresponds to the point the moment at 
which the first cracks become visible and coincides with the change of slope in the envelope curve. The detection of the cracking point was validated by means of Digital Image Correlation. The ultimate drift $\delta_{u}$ is defined as the points at which the lateral strength drops to $80 \%$ of $H_{\max }$. The ultimate strength $H_{u}$ is defined as the maximum load of the bilinear idealization and is determined so as to produce a bilinear curve enveloping the same area as the experimental envelope curve up to $\delta_{u}$. The yielding drift $\delta_{y}$, which corresponds to the is the displacement at the idealized elastic limit, is defined as the ratio between the ultimate strength $H_{u}$ and the effective stiffness $K_{e}$. The ductility factor $\mu$ is computed as the ratio between the ultimate displacement $\delta$ and the yielding displacement $\delta_{y}$ following Eq. (2).

$$
\mu=\frac{\delta_{u}}{\delta_{y}}
$$

Increasing the number of LDS reinforcement layers leads to an unarguably better performance of the strengthening system in terms of lateral load-bearing capacity. As previously mentioned, specimens with one layer of LDS showed a moderate peak load enhancement of about $42 \%$, while those retrofitted with two layer LDS-DL evidenced a peak load significant enhancement of about $59 \%$. However, such enhancement was achieved not only at the expense of ductility but also by exhausting the compressive strength of the masonry. Figure 10 shows that the addition of the extra layer of LDS reduced the enhancement in ductility of one half, since the specimens failed after reaching the compressive strength 422 of masonry. An average enhancement of about $48 \%$ for one reinforcement layer (with respect to the unreinforced case) dropped to $18 \%$ for two reinforcement layers.

Figure 11 shows the resistance domain of the masonry wall. The domain is built considering the experimental vertical and horizontal load recorded at each amplitude step during the testing of the URM specimens and the three specimens that experienced toe-crushing. Figure 11 also defines the point in the resistance domain at which the failure shifts from flexural failure to diagonal 
430

shear failure, marked with a vertical dashed line, and the limit value of the compressed strut of the URM. As mentioned before, such value was computed following the equation provided by the Italian Guideline [25], which yielded a value equal to $245 \mathrm{kN}$.

Figure 11 graphically confirms the failure mechanism experienced by each specimen. Both URM specimens experienced shear failure, while the retrofitted specimens reached the compressive strength of the diagonal strut, as a results of the level of strengthening, which led to the failure of the masonry prior to 38 properly exploit the tensile capacity of the applied reinforcement. In the case of specimen LDS_2, the toe-crushing was experienced after the delamination of the SRG and consequently the masonry was able to transfer the carrying load to the retrofitting solution allowing a more ductile behaviour, which is not the case of specimens retrofitted with two layers of LDS. Finally, the shear compression resistance domains evidenced how the presence of the reinforcement increased the capacity of the masonry in terms of shear behaviour.

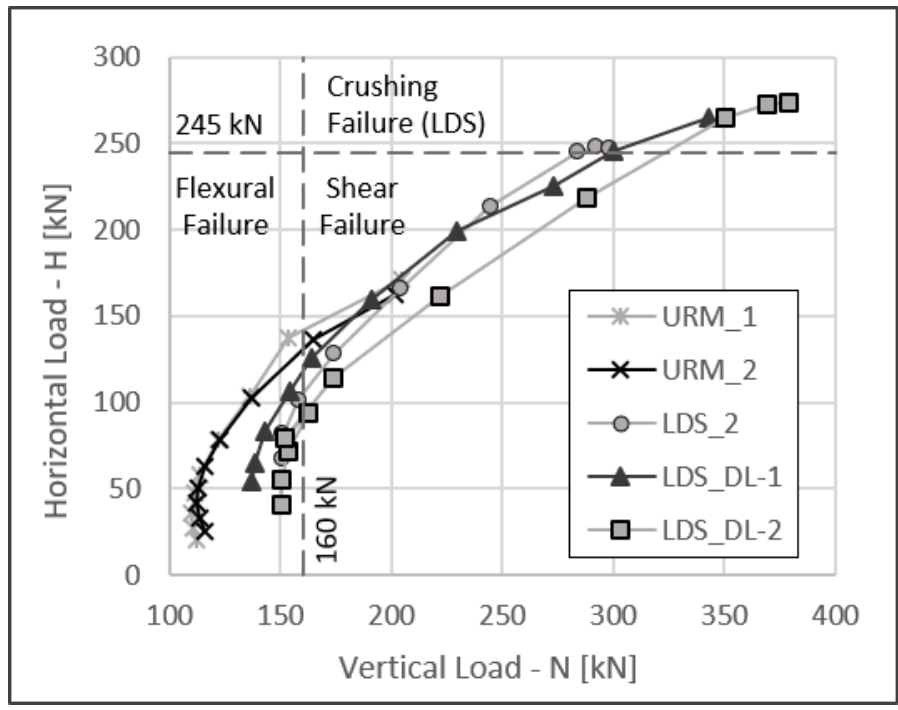

Figure 11: Experimental interaction curve of URM and specimens showing masonry crushing. Definition of the predominant failure modes of the resistance domain.

A correlation study was carried out in which a reinforcement ratio $\rho$ was 
446

$$
\rho=\frac{A_{S R G} E_{f}}{A_{n} E_{m}} 100
$$

Table 3: Reinforcement ratio $\rho$ of studied SRG reinforcement solutions

\begin{tabular}{|c|c|c|c|}
\hline & $A_{n}[\mathrm{~mm}]$ & $E_{m}[\mathrm{MPa}] 20$ & \\
\hline Masonry & 393700 & 2318 & \\
\hline SRG Solutions & $A_{T R M}[\mathrm{~mm}]$ & $E_{f}[\mathrm{MPa}]$ & $\rho$ \\
\hline LDS & 67.2 & 190 & 1.4 \\
\hline LDS-DL & 134.4 & 190 & 2.8 \\
\hline
\end{tabular}

To better understand the influence that the number of layers comprised in

454 the SRG solutions may entail on the final lateral load capacity and ductility, the increment of both parameters was correlated with the computed ratio $\rho$ for each SRG solution.

Figure 12 illustrates that the percentage of enhancement in terms of lateral load-bearing capacity of the strengthened walls, when compared to URM, increases proportionally with the reinforcement ratio. However, the experimental evidence showed that walls strengthened with higher reinforcement ratios, as for instance 2.80, failed due to toe-crushing of masonry. Therefore, despite this linear correlation, $\rho$ should be controlled in order to avoid reaching the compressive strength of masonry before properly exploiting the tensile capacity of the textile comprised in the SRG. Figure 12 also shows an inverse linear correlation between the reinforcement ratio and the ductility increment $(\Delta \mu)$, confirming 
that a higher ratio $\rho$, achieved by overlapping layers of LDS, may increase the lateral load-bearing capacity at the expense of the ductility, as a consequence of attaining the compressive strength of masonry on the diagonal strut. The intersection of the two lines in Figure 12 emphasizes the concept of an optimal reinforcement ratio. This value denotes a balance between the increment of load capacity and ductility. The optimal $\rho$ is equal to 1.68 and for this ratio, 42 the increment of both parameters is equal to $43 \%$. The findings are consistent with the results of different experimental campaigns available in the literature [27, 13, 2, 4].

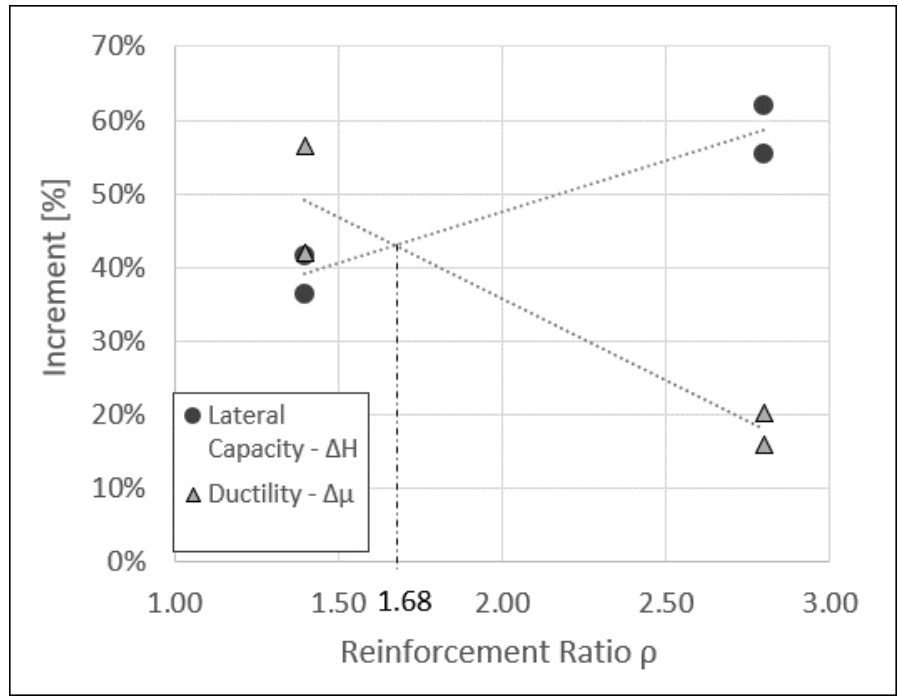

Figure 12: Correlation between the reinforcement ratio and the lateral capacity increment $(\Delta H)$ and the ductility increment $(\Delta \mu)$

\subsection{Energy dissipation and damping coefficient}

The amount of dissipated energy $E_{d}$ was calculated for the first cycle of each displacement amplitude, following [28]. For the corresponding cycle the dissipated energy $E_{d}$ was calculated as the area within the hysteretic loop. The calculation was only done for completed cycles.

480

Figure 13 shows, for each specimen tested, the cumulative energy dissipation $E_{D}$, obtained by summing the dissipated energy of each displacement amplitude 
$E_{d}$. As expected, the SRG provided the URM walls the ability to dissipate more energy by allowing them to reach larger imposed displacements. All the specimens showed a similar trend until reaching the displacement corresponding to the peak load of the URM walls $\left(\delta_{H_{\max }}=10.9 \mathrm{~mm}\right)$. Afterwards, the retrofitted specimens, independently from the number of reinforcement layers, showed a steady increase in the energy dissipation as a result of the capacity of SRG to carry tensile stress levels much higher than those resisted by the URM, and to distribute them over the strips. As the steel cords did not reach the failure, the tensile capacity of the LDS was not fully exploited by any of the reinforcement configurations before the masonry crushing occurred.

The presence of the second layer had only a slight influence on this parameter. In fact, Figure 10 shows a lower percentage of enhancement for LDS-DL specimens. The almost null influence of the second layer on the dissipation capacity may be explained as consequence of the lack of damage due to delamination exhibited by the strips and the severe crushing on the corner of the walls. As a result, the failure of the specimens occurred before the masonry was able to fully transfer its tensile stress to the SRG.

The equivalent viscous damping $\xi_{e q}$ is a good indicator of the energy dissipation capacity and the stability of the hysteresis behaviour [29]. It can be computed as the ratio between the energy dissipated in each completed cycle $E_{d}$ and its corresponding elastic energy $E_{S o}$ following Equations 4 and 5 . In the latter equation $\delta$ represents to the displacement amplitude of each cycle and $K$ is the corresponding secant stiffness to the experimental curve.

It is important to note that the equivalent viscous damping is intended to model the energy dissipation at deformation amplitudes within the linear elastic range of the overall structure. Over this range of deformation, the damping coefficient may vary with the deformation amplitude. Therefore, the damping coefficients compared in Figure 10 are the results of computing the damping coefficient associated only with the linearly elastic behaviour of the wall. It was observed that up to the cracking point, corresponding with the limit of the linear elastic behaviour of the wall, the value of this parameter remained almost 
constant.

$$
\begin{gathered}
\xi_{e q}=\frac{1}{4 \pi} \frac{E_{d}}{E_{S o}} \\
E_{S o}=\frac{K \delta^{2}}{2}
\end{gathered}
$$

Similar to $E_{D}$, in Figure 10 it is observed that the increasing number of LDS layers had a minimal effect on the value of the equivalent viscous damping. Table 2 shows that the LDS-DL specimens present only a slight increment when compared to the LDS specimens. The negligible influence of the number of reinforcement layers on $\xi_{e q}$ can be explained as due to the fact that this parameter is only associated to the linear elastic limit of the structure. Therefore, the SRG reinforcement, regardless of the number of layers, does not play a major role in its definition, since SRG starts working after the cracking of the masonry.

222 Consequently the parameter $\xi_{e q}$ takes a fairly constant value throughout all the tested specimens.

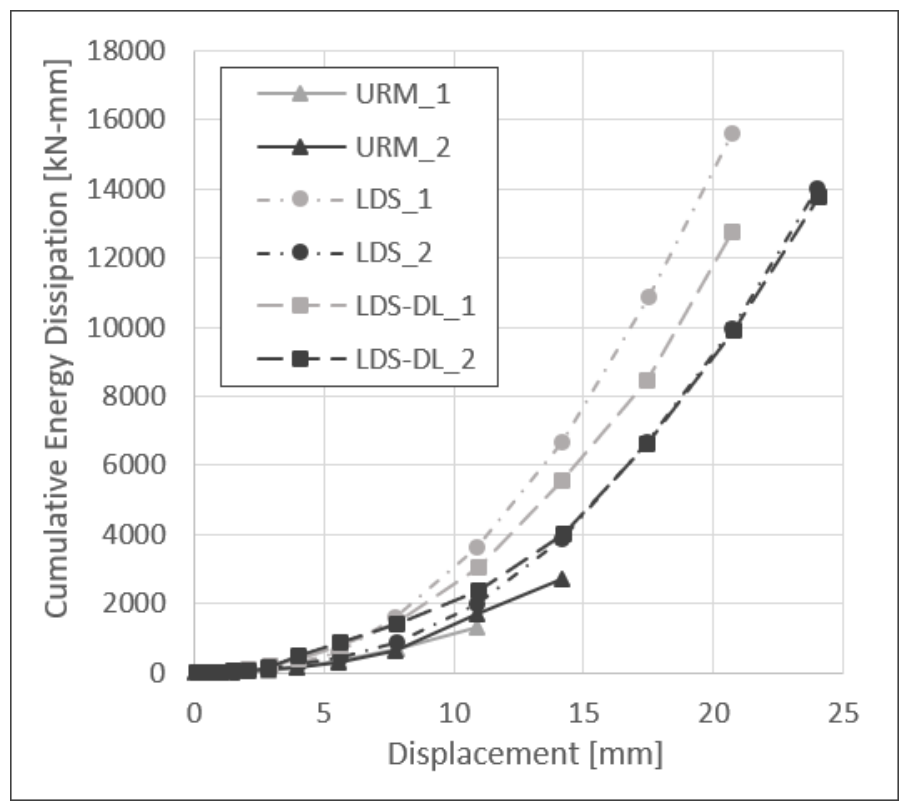

Figure 13: Cumulative energy dissipation vs. displacement of all tested specimens 


\subsection{Efficiency of $S R G$}

The exploitation ratio is a useful parameter to evaluate the effectiveness of the strengthening solutions and contributes to the decision-making regarding the improvement of the seismic performance of reinforced masonry structures.

The exploitation ratio, which accounts for the percentage of the textile's usable tensile strength, is computed as the ratio between the tensile capacity of the reinforcement $f_{f d}$ and the ultimate tensile strength of the textile $\sigma_{u, f}$ presented in Table 1 . The tensile capacity $f_{f d}$ takes the value equal to $\sigma_{u, f}$ when the failure of the reinforcement is due to fibre rupture in tension, which is normally the case of glass and basalt textiles, and the value $\sigma_{s l, t}$ when the failure is due to debonding, associated mainly to the response of steel textile. The term $\sigma_{s l, t}$ is obtained from the single lap-shear bond test following [25].

The value of $f_{f d}$ characterising LDS specimens, was provided by the experimental results in the available literature [6, 11, 7]. As mentioned in Section 4.1,

LDS specimens experienced delamination within the matrix followed by debonding from the substrate without evidencing textile rupture. As a result, it can be assumed that the single-layer LDS strips, applied on the LDS specimens in the experiments herein presented, attained $f_{f d}$ equal to the $\sigma_{s l, t}$. The effectiveness of this solution can be reflected in the computation of a good exploitation ratio equal to 0.75 .

In the case of the LDS-DL specimens, no experimental characterization is currently available on delamination of SRG with two layers of LDS textile.

546 Therefore, there is no information on the value of $f_{f d}$ for this type of solution. Thus, to provide better insight on the efficiency of this strengthening 54 solution, the recordings of the LVDTs were analysed. As previously mentioned, two LVDT sensors were installed on each side of the specimens perpendicularly to the two diagonals where the main cracks were expected. Figure 14 includes the values registered in the LVDTs, divided by their reference length measured 52 before test and averaged to obtained the strains, versus the horizontal load attained by the specimens. The figure shows the Load-Strain $(H-\varepsilon)$ envelope curve constructed by connecting the peak force at the first cycle of each dis- 
placement amplitude of the test. The pushing load (negative value) generate

elongation of the LVDT1 (negative strain values) and shortening of the LVDT2 (positive strain values). The pulling load (positive value) generate an opposite behaviour.

With the aim of providing an approximate value of the tensile capacity $f_{f d}$ to the solution of SRG with two layers of LDS textile, the elongation LVDT readings (negative strain values), of both solutions, were analysed and compared. Since the LVDTs were installed on the top mortar layer of the SRG reinforcement, the recorded values cannot be considered as the strain experienced only by the steel fibre but that of the first top layers of the SRG package. However, the reading may provide a qualitative insight on the effectiveness of the solution by analysing the tensile strains recorded by the LVDTs, on each strengthening solutions for the same stages of the test.

To draw some conclusions regarding the level of stress experienced by the double layer solution, the tensile strains extracted from the LDVTs recordings, on both strengthening solutions, were compared in Figure 14. The strains experienced by each solution were evaluated for the same displacement amplitude of the test. This stage corresponds to the ultimate displacement $\delta_{u}$ for the pushing and pulling direction. In the figure, the analysed strains are marked with a triangle, dark grey in the case of LDS and light grey for LDS-DL. The strains corresponding to the double layer strengthening solution (light grey triangle) are significantly lower when compared to the strain recoded by the LVDTs in the single layer strengthening solution (dark grey triangle). The ratio between the strains experienced by each strengthening solution is almost equal to 0.50 . Therefore, it can be assumed that the level of tensile stress experienced by SRG of the LDS-DL specimens is within half of that experienced by the LDS specimens. This hypothesis is also validated by the fact that LDS-DL specimens did not evidence debonding nor delamination of the SRG but failed as a consequence of toe-crushing. Such failure can be attributed to its high level of strengthening which led to the crushing of the masonry before it was able to fully transfer the tensile stress to the textile, resulting in a less effective strengthening solution. 


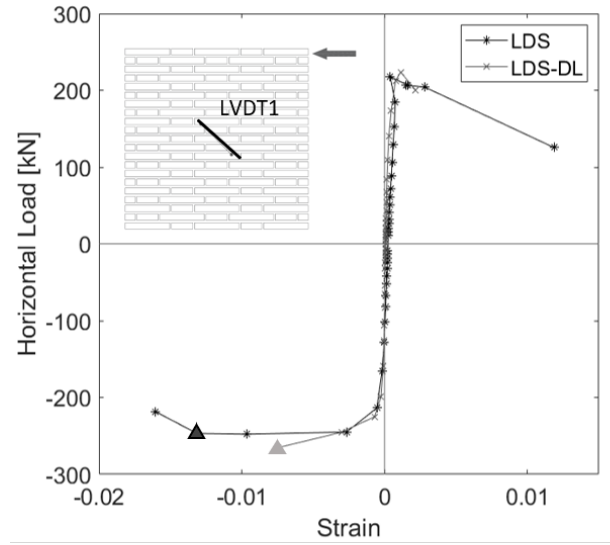

a)

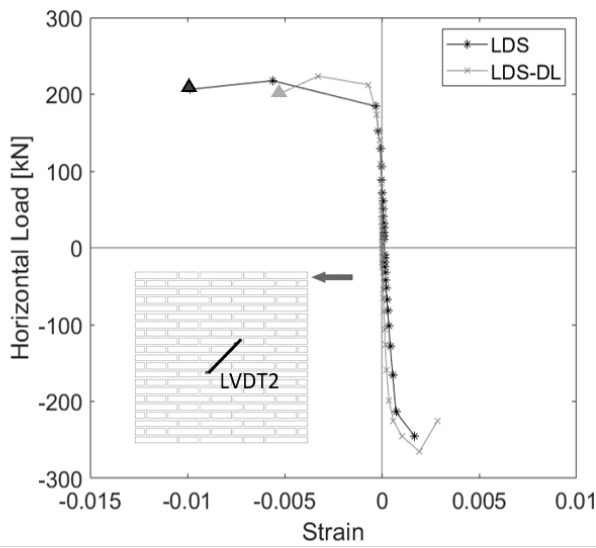

b)

Figure 14: Comparison of horizontal load vs strain experimental curves derived from singleand double-layer SRG specimens: a) LVDT1, b) LVDT2

\section{Conclusions}

This research has investigated the influence of the number of layers of LDS strips on the cyclical shear behaviour of masonry walls retrofitted with SRG. The experimental programme comprised cyclic shear compression tests, with initial pre-compression equal to $0.30 \mathrm{MPa}$, on six masonry samples including two unreinforced one and four walls retrofitted with SRG. The latter were reinforced with one or two layers of LDS strips. The main conclusions of the research can be summarized as follows:

- The presence of SRG with one layer of LDS allowed a proper redistribution of stresses throughout the strips, and therefore, the specimens could withstand larger imposed loads and displacements, proving the efficiency of the strengthening technique.

- Increasing the number of layers of the LDS textile changed the failure mode from shear failure to toe-crushing of the masonry, which indicates that the level of strengthening was excessive causing the masonry crushing before properly exploiting the capacity of the SRG solution. 
- Both SRG solutions showed a significant enhancement of the lateral loadbearing capacity. However, it was observed that in LDS-DL specimens such enhancement was provided at the expense of ductility. In fact the extra layer of LDS applied in LDS-DL specimens did not provide any extra enhancement in terms of displacement capacity.

- Due to the small thickness of the sheets of steel fabric, the application of the second layers had minimal influence on the parameters corresponding to the initial linear stage of the test such as the effective stiffness $K_{e}$, and damping coefficient $\xi_{e q}$.

- The presence of SRG provided masonry with the ability to dissipate more energy by sustaining lager imposed displacements. However, and as consequence of the masonry crushing due to the excessive strengthening, the second layer of LDS in LDS-DL specimens had almost null action on the dissipation mechanism of the specimens.

- Further experimental campaigns could be conducted to broad the available experimental database comprising SRG with multiple layers to validate the findings on the correlation between reinforcement ratio and in-plane response.

\section{Acknowledgements}

The authors gratefully acknowledge the financial support from the Ministry 222 of Economy and Competitiveness and from the Ministry of Science, Innovation and Universities of the Spanish Government, as well as that of the ERDF

224 (European Regional Development Fund) through the project SEVERUS (Multilevel evaluation of seismic vulnerability and risk mitigation of masonry buildings 26 in resilient historical urban centres, Ref. num. RTI2018-099589-B-I00). The reinforcement systems and construction of the specimens for the experimental programme have been funded by Kerakoll Spa through the RTD project "Seismic Strengthening of Masonry Walls" (Ref. num. A-01278). The authors wish 
to thank Paolo Casadei, José Luis Sanchez and José Dobón from Kerakoll Spa for their involvement and support. The support from Secretaria d'Universitats i Investigació de la Generalitat de Catalunya through a predoctoral grant awarded to the first author is also gratefully acknowledged.

\section{References}

[1] A. Penna, P. Morandi, M. Rota, C. F. Manzini, F. Da Porto, G. Magenes, Performance of masonry buildings during the Emilia 2012 earthquake, Bull. Earthq. Eng. 12 (2014) 2255-2273. doi:10.1007/s10518-013-9496-6.

[2] X. Wang, C. C. Lam, V. P. Iu, Experimental investigation of in-plane shear behaviour of grey clay brick masonry panels strengthened with SRG, Eng. Struct. 162 (2018) 84-96. doi:10.1016/j.engstruct.2018.02.027. URL https://doi.org/10.1016/j.engstruct.2018.02.027

[3] L. Garcia-Ramonda, L. Pelá, P. Roca, G. Camata, In-plane shear behaviour by diagonal compression testing of brick masonry walls strengthened with basalt and steel textile reinforced mortars, Constr. Build. Mater. 240 (2020). doi:10.1016/j.conbuildmat.2019.117905.

[4] F. Ferretti, C. Mazzotti, FRCM/SRG strengthened masonry in diagonal compression: experimental results and analytical approach proposal, Constr. Build. Mater. 283 (2021). doi:10.1016/j . conbuildmat. 2021.122766 URL https://doi.org/10.1016/j . conbuildmat.2021.122766

[5] J. Yacila, J. Salsavilca, N. Tarque, G. Camata, Experimental assessment of confined masonry walls retrofitted with SRG under lateral cyclic loads, Eng. Struct. 199 (April) (2019). doi:10.1016/j.engstruct.2019.109555.

[6] S. De Santis, G. de Felice, Steel reinforced grout systems for the strengthening of masonry structures, Compos. Struct. 134 (2015) 533-548. doi: 10.1016/j.compstruct.2015.08.094. 
656

658

660

[8] S. De Santis, F. Ceroni, G. de Felice, M. Fagone, B. Ghiassi, A. Kwiecień,

662

$664 \quad \square$

666

घ of mortar matrix in the bond behavior and salt crystallization resistance

668

670

[10] M. Santandrea, F. Focacci, C. Mazzotti, F. Ubertini, C. Carloni, Determof FRCM applied to masonry, Constr. Build. Mater. 209 (2019) 592-605. doi:10.1016/j.conbuildmat.2019.03.059

70 URL https://doi.org/10.1016/j.conbuildmat.2019.03.059

672 ination of the interfacial cohesive material law for SRG composites bonded to a masonry substrate, Eng. Fail. Anal. 111 (March 2019) (2020).

674 doi:10.1016/j.engfailanal.2019.104322

URL https://doi.org/10.1016/j.engfailanal.2019.104322

[11] M. Santandrea, G. Daissè, C. Mazzotti, C. Carloni, An Investigation of the Debonding Mechanism between FRCM Composites and a Masonry Substrate, Key Eng. Mater. 747 (2017) 382-389. doi:10.4028/www. scientific.net/kem.747.382.

[12] L. Garcia-Ramonda, Seismic retrofit of masonry with innovative materials for strengthening and repair, Ph.D. thesis, Universitat Politècnica de Catalunya (2020).

[13] S. Babaeidarabad, D. C, A. Nanni, URM walls strengthened with fabric- 

CC. 1943-5614.0000441.

[14] C. G. Papanicolaou, T. C. Triantafillou, K. Karlos, M. Papathanasiou, Textile-reinforced mortar (TRM) versus FRP as strengthening material of URM walls : in-plane cyclic loading, Mater. Struct. 40 (2007) 1081-1097. doi:10.1617/s11527-006-9207-8.

[15] A. Napoli, R. Realfonzo, Reinforced concrete beams strengthened with SRP/SRG systems: Experimental investigation, Constr. Build. Mater. 93 (2015) 654-677. doi:10.1016/j.conbuildmat.2015.06.027. URL http://dx .doi .org/10.1016/j . conbuildmat.2015.06.027

[16] CEN, EN 772-1, Methods of test for masonry units. Part 1: Determination of compressive strength (2011).

[17] CEN, EN 772-6, Methods of test for masonry units. Part 6: Determination of bending tensile strength of aggregate concrete masonry units. (2002).

[18] J. Segura, D. Aponte, L. Pelà, P. Roca, Influence of recycled limestone filler

1 additions on the mechanical behaviour of commercial premixed hydraulic

a lime based mortars, Constr. Build. Mater. 238 (2020). doi:10.1016/j. conbuildmat.2019.117722.

URL https://doi.org/10.1016/j.conbuildmat.2019.117722

[19] CEN, EN 1015-11 - Methods of test for mortar for masonry - Part 11: Determination of flexural and compressive strength of hardened mortar. (1999).

[20] J. Segura, L. Pelà, P. Roca, Monotonic and cyclic testing of clay brick and lime mortar masonry in compression, Constr. Build. Mater. 193 (2018) 453-466. doi:10.1016/j.conbuildmat.2018.10.198. URL https://doi.org/10.1016/j.conbuildmat.2018.10.198

[21] CEN, EN 998-2: Specification for mortar for masonry - Part 2: Masonry Mortar (2010). 
[22] Applied Technology Council, Interim Testing Protocols for Determining

[28] C. Knox, Assessment of Perforated Unreinforced Masonry Walls Respond-

[29] S. Ivorra, B. Torres, F. J. Baeza, D. Bru, In-plane shear cyclic behavior of 738 the Seismic Performance Characteristics of Structural and Nonstructural Components - FEMA 461 (2007).

[23] G. Magenes, G. M. Calvi, Cyclic behaviour of brick masonry walls, in: Balkema (Ed.), Proc. Tenth World Conf. Earthq. Eng. 19-24 July 1992 Madrid, Spain, 1992, pp. 3517-3522.

[24] M. Tomaževič, Earthquake-Resistant Design of Masonry Buildings Vol. 1, Imperial Collage Press, 1999. arXiv:arXiv:1011.1669v3 doi:10.1142/9781848160835 URL http://ebooks.worldscinet.com/ISBN/9781848160835/ 9781848160835.html

[25] CNR - Consiglio Nazionale delle Ricerche, DT 215/2018 - Istruzioni per la progettazione, l'esecuzione ed il controllo di interventi di consolidamento statico mediante l'utilizzo di compositi fibrorinforzati a matrice inorganica (in Italian) (2018).

[26] European Standard, Eurocode 8 : Design of structures for earthquake resistance - Part 3: Assessment and retrofitting of buildings. (2004).

[27] C. Papanicolaou, T. Triantafillou, M. Lekka, Externally bonded grids as strengthening and seismic retrofitting materials of masonry panels, Constr. Build. Mater. 25 (2) (2011) 504-514. doi:10.1016/j.conbuildmat.2010. 07.018

URL http://dx.doi.org/10.1016/j.conbuildmat.2010.07.018 ing In Plane, Ph.D. thesis, The university of Auckland (2012). windowed masonry walls reinforced with textile reinforced mortars, Eng.

1. Struct. 226 (November 2019) (2021). doi:10.1016/j.engstruct. 2020. 
111343

URL https://doi.org/10.1016/j.engstruct.2020.111343 